\title{
A IMPORTÂNCIA DA ÁGUA PARA A REPRODUÇÃO DA COMUNIDADE SÃO JOSÉ DO FURO MARACAPUCU, ABAETETUBA - PARÁ ${ }^{1}$
}

\author{
Walter Chile Rodrigues LIMA $^{2}$ \\ SOPREN / UFPA \\ wchile@ufpa.br
}

Resumo: Este estudo tem como objetivo destacar a importância da água para a reprodução da Comunidade ribeirinha São José do furo Maracapucu e a relação com a crença, locomoção, atividades produtivas e hábitos. A metodologia utilizada, quanto à sua abordagem, é de natureza qualitativa descritiva; quanto ao estudo, é bibliográfico e de campo. A amostra da pesquisa foi de 10 famílias de um universo de 105. Para a coleta de dados, foi utilizado questionário com questóes abertas e roteiro de diálogo e observações. A partir da análise dos resultados obtidos, identificouse que a água é imprescindível na construção do gênero de vida do ribeirinho amazônico. Constatou-se, também, que a água do estuário vem sofrendo agressões em consequência do mau uso por diversos seguimentos.

Palavras-chave: Ribeirinho. Água. Reprodução Material.

Abstract: The aim of this study is to highlight the importance of water for reproduction of São José Community riverside populations of the Maracapucu hole and the relation with the belief, locomotion, productive activities and habits. The methodology utilized is of the qualitative descriptive approach, and in relation to the paper is bibliographical and of the field. The survey sample was 10 families from a population of 105 families. Data was collected using a questionnaire with open questions and scripted of dialogue and observations. The analysis of the results identified that water is essential in building the style of life of the Amazon riverside populations. It was observed also that the water of the estuary has been suffering attacks because of the misuse of several segments.

Keywords: Riverside Populations. Water. Material Reproduction.

\footnotetext{
${ }^{1}$ Estudo iniciado no ano de 2005. Dados sistematizados no contexto da disciplina Antropologia e Sociedades Haliêuticas na Amazônia. Ministrada pelas Professoras: Dra. Lourdes Furtado e Dra. Denize Adrião/PPGCS - UFPA - 2007 (cursada na qualidade de aluno especial). Revisto e ampliado em 2010.

${ }^{2}$ Arte-Educador, Especialista em Gerenciamento Ambiental, mestrando do PPGArtes - ICA/UFPA, membro da diretoria da SOPREN, Professor do Curso Técnico de Cenografia da ETDUFPA.
} 


\section{Introdução}

A Região amazônica ${ }^{3}$, situada ao norte do território brasileiro, concebida como uma das singulares áreas úmidas do planeta (FURTADO, 2002) é habitada, assim como o restante do país, por população resultante do contato de três grandes etnias: os índios que aqui viviam, os negros trazidos da África como mercadoria e o branco, oriundo do Velho Mundo. Esse encontro deu origem a um intenso processo de miscigenação, formando um povo de características peculiares e hábitos culturais diversos.

O ribeirinho amazônico, população tradicional também resultante dessa miscigenação, construiu seu gênero de vida em torno da água, fazendo do grande potencial hídrico local algo imprescindível a sua existência.

Essa água fez-se presente nas atividades produtivas do passado, assim como se faz presente nas atividades de hoje, são elas: a cultura do açaí, pesca artesanal, coleta de frutos, captura de camarão, prática de roçado, entre outras atividades intermediárias, não menos importantes.

É, também, indispensável como via de transporte, meio de lazer, ambiente de morada e atuação de personagens do imaginário.

Neste estudo, abordaremos a importância do elemento água para reprodução dos ilhéus do estuário amazônico, situados na Comunidade São José do furo Maracapucu, município de Abaetetuba - PA, destacando sua relevância na construção do gênero de vida da comunidade.

O estudo realizou-se por meio da observação participante e aplicação de questionário com representantes de 10 das 105 famílias existentes no lugar, estabelecendo diálogo entre os dados levantados e as bases teóricas, visando essencialmente conhecer a importância da água para a reprodução da Comunidade São José do furo Maracapucu.

\section{Localização da área de estudo}

O município de Abaetetuba, no Estado do Pará, integra a microrregião de Cametá junto com os municípios de Bagre, Baião,

\footnotetext{
${ }^{3}$ Por Região amazônica, entende-se o território que abarca os Estados do Acre, Amazonas, Amapá, Pará, Rondônia e Roraima, portanto adotando-se o conceito Clássico em detrimento da denominação de Amazônia Legal de criação recente e questionável.
} 
Barcarena, Cametá, Igarapé-Miri, Limoeiro de Ajuru, Mocajuba, Moju e Oeiras do Pará. Essa microrregião está contida na Mesorregião do nordeste paraense (IBGE, 2000 apud MACHADO, 2001, p. 3).

As ilhas de Abaetetuba estão localizadas a oeste da sede do município. São aproximadamente 45 ilhas interligadas por furos de maré e igarapés, principais vias de acesso que possibilitam a comunicação entre uma comunidade e outra e entre as comunidades e a sede do município.

A comunidade São José localiza-se nas margens de seguimento do furo Maracapucu, no perímetro que vai da boca do Igarapé Cariá estendendo-se até a boca da entrada do igarapé Assacueira, no sentido embocadura.

Nas imagens seguintes, apresenta-se o mapa do município de Abaetetuba e o pormenor da área estudada.

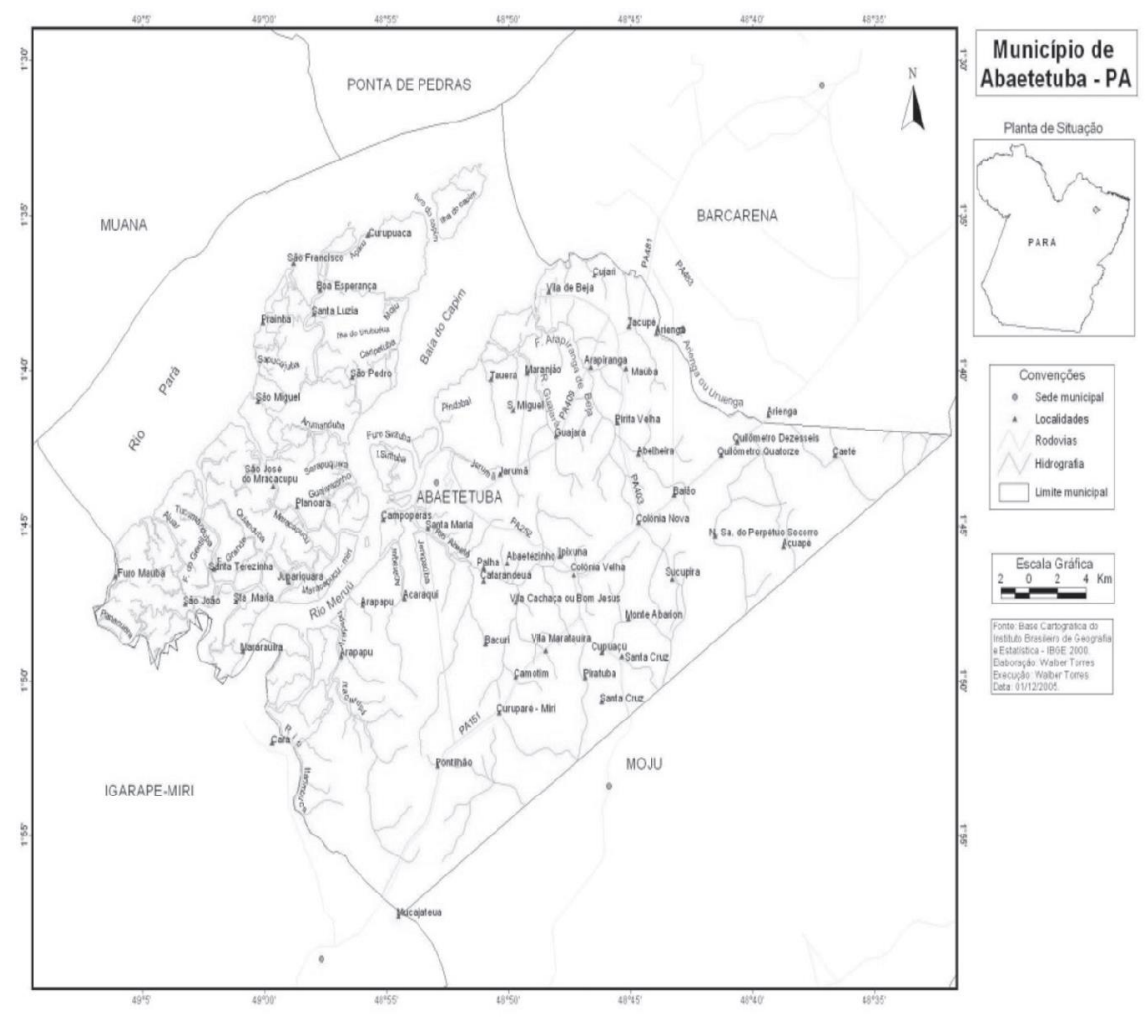

Figura 1 - Mapa do Município de Abaetetuba, Pará. 


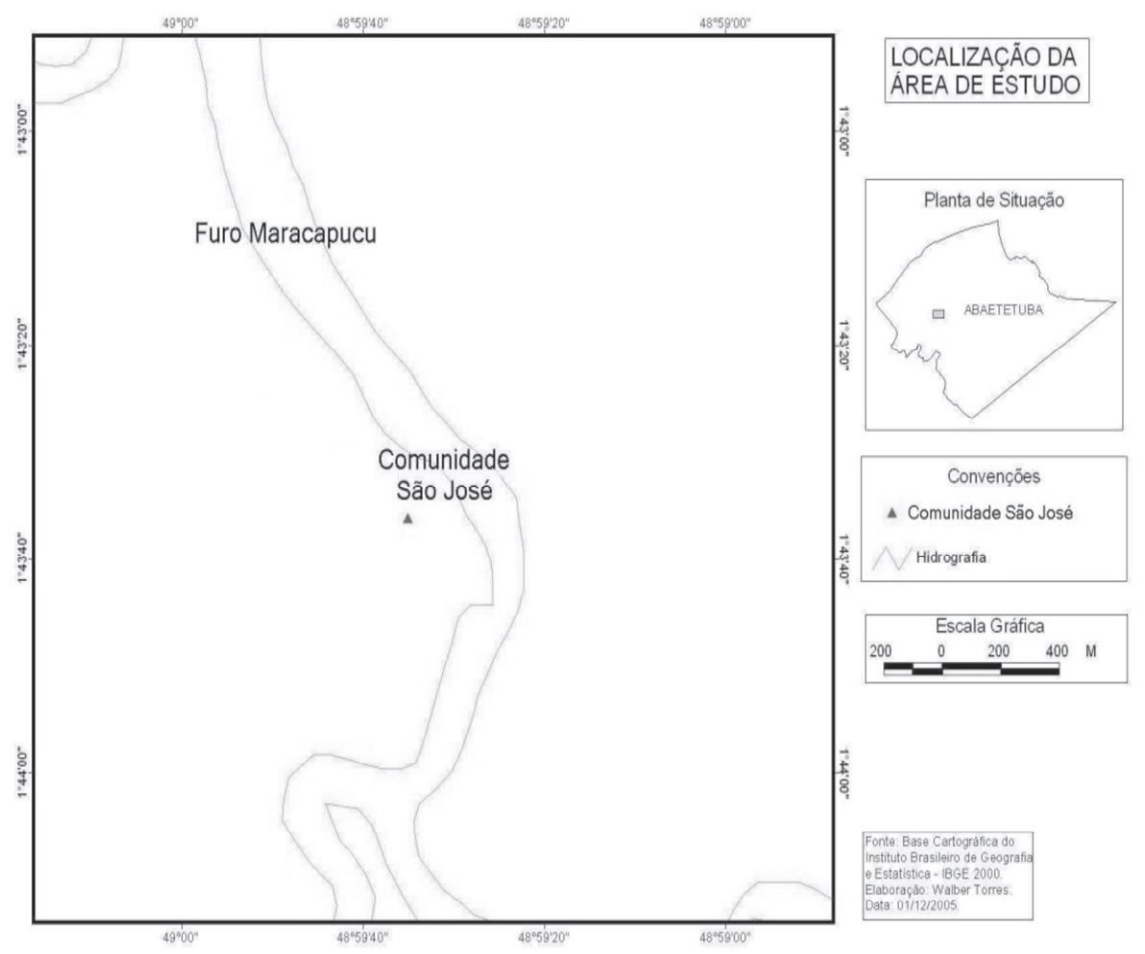

Figura 2 - Detalhe do furo Maracapucu com destaque para localização da Comunidade São José.

O furo Maracapucu sofre influência de diferentes marés e funciona como importante canal de acesso das embarcações que vêm pelo rio Pará e região do Marajó rumo à sede do município de Abaetetuba. Na enchente recebe água tanto da baía do capim quanto do rio Pará. O igarapé Cariá, localizado no Maracapucu, é o divisor dessas águas. Navegando-se toda a extensão do furo tanto na enchente, quanto na vazante, parte da viagem faz-se contra a correnteza e parte realiza-se a favor.

\section{Crença}

Nos furos e igarapés da região das Ilhas, estão instaladas as Comunidades Eclesiais de Base (CEBs), da diocese de Abaetetuba, oriundas da Igreja Católica. Todas possuem santo padroeiro e festejo 
anual, aglutinando os ilhéus da localidade e entorno que, em sua maioria, utilizam, como acesso às sedes das comunidades, os furos e igarapés, obedecendo aos horários das marés, a incidência de chuva, sol e outras imposições naturais e sobrenaturais.

A Igreja Católica, faz-se presente na Região amazônica, desde o período colonial.

Afirma Machado (1996) que data de 1888 a conclusão do primeiro templo religioso no município, e é nesta mesma época, após o período de freguesia, que a igreja de Abaetetuba torna-se paróquia. Na primeira metade do século XX, passa a ser prelazia e a partir dos anos oitenta, deste mesmo século, torna-se diocese. Da diocese de Abaetetuba, faz parte a Paróquia de Nossa Senhora Rainha da Paz, onde funciona a Pastoral das Ilhas que administra as 57 comunidades cristãs em atividade (CEBs), da qual faz parte a Comunidade São José do furo Maracapucu.

A crença do amazônida, que organiza sua vida social e cultural a partir do calendário oficial católico, é que determina as festividades para homenagear seus santos de devoção.

Neste sentido, Galvão (1976), ao realizar estudo em uma comunidade amazônica renomeada por ele de Itá, afirma que a prática do catolicismo é marcada por significativa adoração aos santos padroeiros da localidade e a um pequeno número de santos de devoção. A comunidade tem como santo padroeiro São José, seu festejo acontece em época que compreende ao período de julho a outubro.

A profecia religiosa da maioria das famílias da comunidade é o catolicismo, porém, existe a presença dos evangélicos com cultos frequentes, além de práticas de pajelança. Essa diversidade cultural e religiosa chega aos ilhéus através das águas dos rios que possibilitam a utilização do único meio de transporte, que dá acesso à comunidade, as embarcações, e assim proporcionando dinamismo nas relações interpessoais.

\section{Hidrolocomoção estuarina}

Os meios de locomoção de propulsão humana usados pelos ilhéus são a muntaria e o casco ou casquinho, a bajara e o batelão. Este último, destinado ao transporte de barro e palhas necessita de grandes remos 
chamados de faias para se locomover, deslocando-se sempre a favor da maré, nessa relação próxima e indispensável com esse patrimônio natural que é água para a comunidade ribeirinha. Utiliza-se também barcos movidos a motor de modelos diversos como os botes, as rabetas e o rabudinho, este último de aparecimento recente está muito em voga no lugar. A muntaria é uma canoa composta, grosso modo, de três tábuas, sendo uma ao centro e as duas demais dispostas lado a lado, já o casco tem sua forma esculpida do corpo de uma árvore.

As embarcações de propulsão humana deslocam-se com o auxílio do remo. De acordo com os ilhéus, as embarcações estão preparadas para uso quando suas fendas são calafetadas com algodão, massa própria e zarcão, e pintadas com o nome de batismo que é impresso nas laterais e proa $^{4}$ da canoa. Outros calafetam as fendas das embarcações com bucha de miriti e tabatinga ou barro da beira de barranco. Ambas são usadas para deslocamentos de distâncias pequenas e médias, sempre que possível, seguindo o movimento da maré.

Das embarcações de propulsão a motor, merece destaque o chamado rabudinho, que consiste num casquinho ou muntaria, o qual recebe um motor portátil movido à gasolina. Possui eixo móvel que formando conjunto com a hélice assumem a função de leme. Sua capacidade é para no máximo 3 pessoas.

O rabudinho é utilizado para percorrer distâncias pequenas e médias. A composição motor de boa rotação e casco pequeno faz dele um artefato de rápido deslocamento pelas águas dos furos e igarapés da região das ilhas de Abaetetuba. Ressalta-se que esta concepção de embarcação não foi criada no município, existe registro de sua existência na região do Amazonas e em Marabá no Estado do Pará.

O rabudinho representa tanto um meio de rápido deslocamento, quanto uma alternativa de proteger o bem material da pirataria. O motor por ser portátil não necessita de fixação permanente no casco, ele pode ser levado para o interior do domicílio a todo e qualquer momento, e desta

\footnotetext{
${ }^{4}$ Essa modalidade chama-se, no lugar, de abertura de letras, e o profissional, pintor de letras. Há grande aceitação por parte dos ribeirinhos pelos tipos de letras rebuscadas e sombreadas. Essa atividade encontra-se em via de extinção pela carência de novos profissionais.
} 
forma, escondendo-o dos criminosos. A pirataria está em expansão na Região e uma solução governamental eficaz parece muito distante.

Seduzidos pela velocidade, alguns ilhéus confeccionam o casco dos rabudinhos com a madeira marupá (Simaruba amara), por ser leve e proporcionar melhor performance da embarcação, apesar de sua pouca durabilidade. No bojo da facilidade de deslocamento a imprudência dos mais jovens se faz presente, pois ao realizarem disputas de velocidades entre rabudinhos, chamada de pofía, acidentes com vítimas começam a acontecer.

Objetivando a visualização de alguns modelos de embarcação, elaborou-se o desenho, apresentado em seguida:

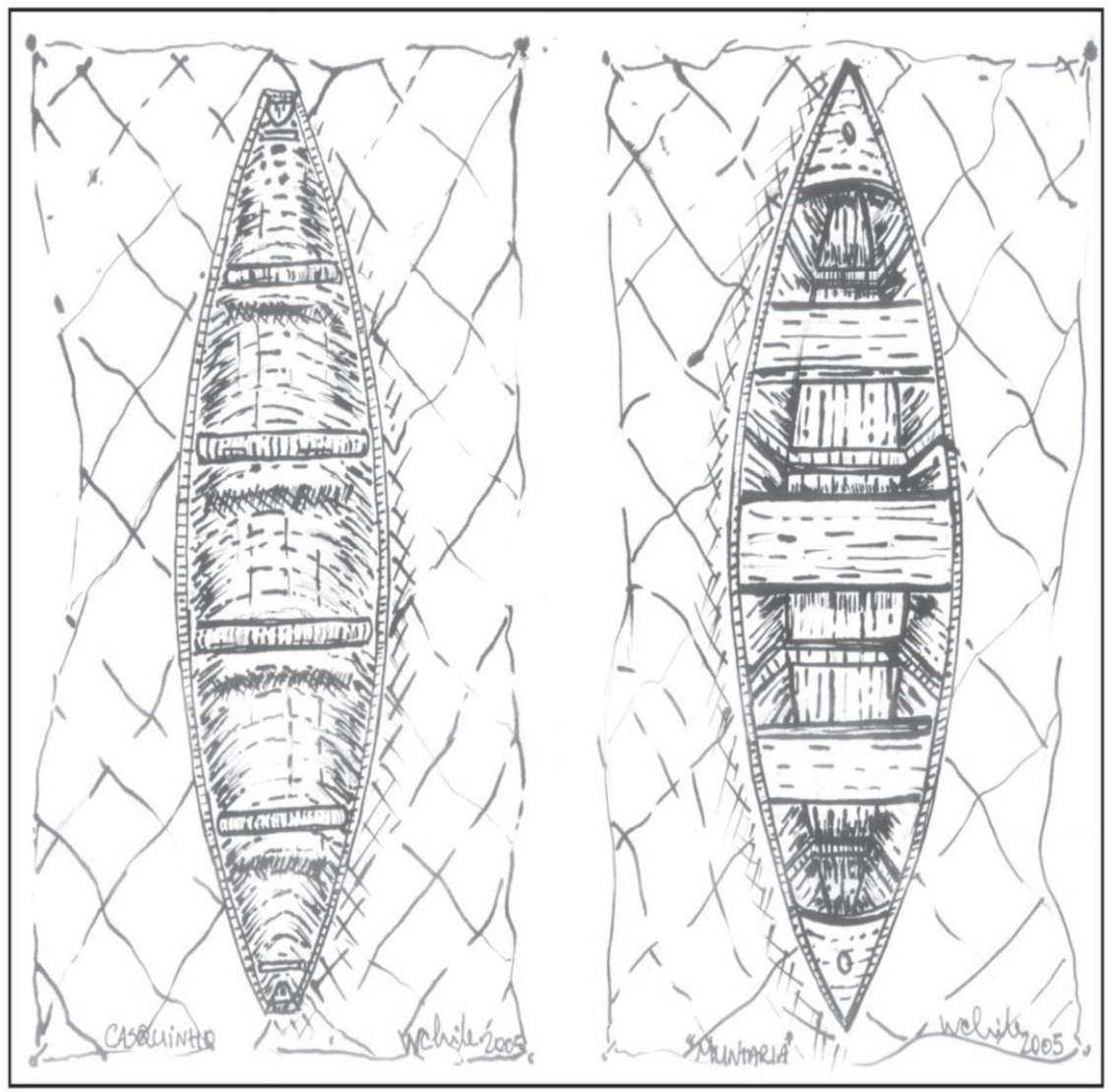

Figura 3 - Modelos de embarcação. Fonte: Casquinhos. Foram utilizados bicode-pena e nanquim sobre papel. Confeccionados pelo autor. 
O deslocamento para a cidade é feito por meio das freteiras, embarcações motorizadas de porte pequeno e médio, destinadas a transportar mercadorias diversas e pessoas. Partem, diariamente, rumo à sede do município a partir das $4 \mathrm{~h}$, variando de acordo com o tempo das águas.

Para chamar o freteiro, que passa no leito do furo Maracapucu coletando os passageiros antes do amanhecer, os ilhéus utilizam como instrumento de comunicação, uma lamparina acesa, alimentada a querosene, que é movimentada com as mãos. A gesticulação de membros superiores, portando a fonte luminosa, indica ao freteiro que alguém está solicitando passagem para a sede do município.

O ilhéu faz da sua embarcação a extensão de sua moradia sobre as águas, estabelece uma relação afetuosa, a ela dedica tempo, carinho e apreço. É a embarcação, por mais simples que seja, que lhe permite transitar pela localidade, conduzir sua família, colocar e despescar as armadilhas de pesca, transportar o açaí e o produto de toda e qualquer atividade que desenvolva, leva-o ao culto de sua confissão religiosa, ao festejo do santo, permitindo assim o contato com seus pares.

\section{Habitação e hábitos à beira da água}

O ilhéu constrói sua casa na margem dos furos e igarapés, com altura pouco superior ao nível das águas de sizígias. Utilizando a matéria prima que o ambiente oferece, as casas são confeccionadas de madeira e cobertas com telhas de barro ou mesmo com palhas. Em algumas, somente os esteios são de madeira, as paredes e o assoalho são de paxiuba ${ }^{5}$. As janelas são confeccionadas com madeira branca ou com ripas extraídas das buchas de miriti.

A grande maioria das casas possui três cômodos: a sala ou salão onde praticamente todos dormem; a cozinha onde se prepara e consome os alimentos; e a camarinha, quarto reservado, destinado à privacidade do casal que exerce a função de chefe da casa.

\footnotetext{
${ }^{5}$ Caule do açaizeiro partido no sentido do comprimento formando, portanto, duas tábuas que são utilizadas para a construção de assoalho, paredes, pequenas pontes, chiqueiros, galinheiros e outras construções de porte singelo.
} 
Dormem em rede, e bem cedo, logo que escurece, isso nas casas que não possuem televisão, as que possuem desligam o aparelho logo após a chamada novela das oito que é veiculada de segunda a sábado na televisão. A rotina é alterada quando tem jogo de futebol, principalmente da seleção brasileira, mesmo com isso, raramente ficam dormindo até tarde. Acordam no dia seguinte, antes mesmo do nascer do sol.

O sanitário é, geralmente, fora da casa e a fossa é do tipo aberta ou negra. Confeccionado em madeira, o sanitário é coberto com palha ou telhas de barro. Possui assento para duas ou mais pessoas, pois é hábito a realização das necessidades fisiológicas em conjunto por parentes ou pessoas próximas, estabelecendo uma boa conversa ou até mesmo fumando um porronca ${ }^{6}$.

O banho dá-se no porto com a maré cheia, o qual muda sempre de horário em função da dinâmica natural da maré. O horário do banho, é um dos momentos de lazer em família. Reúnem-se algumas vezes nas marés de verão para se banhar, envolvidos em conversas que podem demorar horas.

A relação do ilhéu do estuário amazônico com a água é muito intensa. Para manter a proximidade com este recurso natural, até mesmo na baixa maré, e ultrapassar a condição de isolamento naturalmente imposta, ele buscou maneiras e desenvolveu meios de se relacionar, colocando na frente da casa o caule de um miritizeiro (Maurithia flexuosa) $)^{7}$, em posição horizontal, com a função de extensão sólida, o qual possibilita o acesso à água do rio, mesmo quando a maré está distante.

O miritizeiro é preso por duas varas, chamadas de varejão ou mará, que atravessam as suas extremidades e são fixadas no porto de forma que, tanto na maré cheia como na seca, com um pouco de habilidade motora ampla, é possível caminhar sobre ele.

Costumam reunir-se para as principais refeições, comem utilizando como instrumento imprescindível a colher. Almoça-se por volta das $11 \mathrm{~h}$ e não pode faltar, na dieta alimentar dos ribeirinhos, a tigela contendo açaí e farinha d'água colocada ao lado de uma porção de carne, camarão ou

\footnotetext{
${ }^{6}$ Cigarro artesanal confeccionado com tabaco e folha de abade.

${ }^{7}$ Palmeira de grande porte. Segundo os ilhéus, uma pessoa é paupérrima quando ela não possui nem o miritizeiro da porta da casa.
} 
peixe, seja ele fresco, do gelo ou mesmo de salga. Jantam sempre no final da tarde, algumas vezes repetindo o cardápio do almoço.

Durante o verão, é comum ao ilhéu alimentar-se pela manhã com mingau de farinha ou arroz misturado com o suco, extraído de frutas como miriti, açaí e bacaba ${ }^{8}$. Já no inverno amazônico ${ }^{9}$, período de entressafra, particularmente do açaí, aparece um novo tipo de mingau; é o chamado mingau baré, feito de farinha d'água, peneirada ou não, cozida com água e sal.

Os comunitários casam geralmente com pessoas do entorno ou de comunidades vizinhas, algumas vezes com pessoas de outros lugares. Segundo os ilhéus, casamento entre membros das localidades do Ipiramanha e Cariá ${ }^{10}$, dá sempre certo.

Quando acontece o óbito de algum membro da comunidade, o corpo é velado na localidade, em determinada hora, quando formado o cortejo fúnebre e o estágio da maré permitir o deslocamento, as pessoas se dirigem a bordo de barcos movidos a motor de propriedade de parentes, vizinhos e compadres em forma de procissão fluvial, com a embarcação transportando o finado à frente, e as demais, logo atrás, rumando em direção ao cemitério, localizado na sede do município. Quando um membro da família ou da comunidade morre na cidade, lá mesmo ele é velado seja na casa de um parente ou compadre e em seguida enterrado no cemitério municipal.

Em respeito à memória do falecido ou falecida, os ilhéus mais antigos, costumam usar um retalho de tecido preto chamado de fumo, que é fixado por um alfinete na vestimenta, do lado esquerdo do peito, nos primeiros dias, após o falecimento. Só passam a freqüentar festas, inclusive a dos santos de devoção, a partir de um ano do acontecido e momentos de lazer como os banhos de maré sofrem restrições, devendo, nos primeiros dias após o óbito, serem rápidos e silenciosos. Costumes não comuns, entre os jovens.

\footnotetext{
${ }^{8}$ O suco dessas frutas é chamado pelo ilhéu de vinho.

${ }^{9}$ O inverno para o amazônida, ao contrario do que ocorre em outras regiões do país, acontece na Região durante o período de maior intensidade pluviométrica, e isso se dá nos primeiros meses do ano.

${ }^{10}$ Igarapés que possuem comunicação hidrográfica com o furo Maracapucu, nos limites da Comunidade São José.
} 


\section{5 Água e reprodução material: ontem e hoje}

O ambiente de reprodução material dos ilhéus do estuário amazônico sofre influências do movimento periódico das águas; pesca, pequena agricultura, coleta dos principais frutos da várzea como açaí, miriti e o corte de lenha, entre outras atividades, são ajustadas a esse movimento cíclico, envolvente proporcionado pela sazonalidade das marés.

Hiraoka e Rodrigues (1997, p. 77) sustentam que:

Análogo as outras partes ribeirinhas da Amazônia, o povo estuarino participa desde o século dezoito da economia de mercado. O cultivo de cacau e canade-açúcar em pequena escala introduzidos pelos jesuítas, sobreviveu as flutuações do mercado por dois séculos até sua eliminação na década de 1970. O sangramento das seringueiras (Hevea brasiliensis) nativas ocorreu entre 1860 e 1970, mas o número reduzido de árvores na várzea de maré não trouxe o boom econômico análogo ao das regiões ocidentais da Amazônia.

Percebe-se que o povo do estuário amazônico tem participação historicamente construída no mercado com uma produção diversificada ajustada ao movimento das marés.

Merece destaque, também, a exportação de ostras ou conchas que eram coletadas nas praias do estuário e destinadas à confecção de pentes, botões e outros artefatos.

A coleta de sementes de espécie azeiteiras, que sobreviveu até os anos 80 do século $\mathrm{XX}$, era realizada por todos os membros da família, a bordo de cascos e muntarias. Era realizada tanto na enchente, como na vazante. A estratégia adotada consistia em remar sempre contra a correnteza, como uma forma de maior desempenho na coleta das sementes que vinham no lixo da maré. Para retirar as sementes azeiteiras que vinham buiando na maré, utilizava-se um artefato chamado de mãode-juda ou mão-de-ajuda, que é um pequeno paneiro fixado na ponta de uma vara com o comprimento de $1 \mathrm{~m}$ a $1^{1 / 2} \mathrm{~m}$. 
Era comum encontrar, até o final da década de 80 , do século xx, na frente das casas de comércio ou tabernas dispostas nas margens dos diversos furos e igarapés da região das Ilhas de Abaetetuba, uma espécie de tanque construído em madeira, fixado na praia da várzea, possuindo um tampão que abre e fecha na parte superior. Esse reservatório era construído com a finalidade de armazenar o leite coagulado da seringueira, chamado em Abaetetuba de sernambi.

Guardados estrategicamente nestes depósitos para receber as duas visitas diárias da maré, o sernambi não desidrataria e nem perderia peso na hora de ser comercializado.

Já o cultivo de cana-de-açúcar, que se deu intensivamente na região de várzea, com visitas diárias das águas e da chamada maré de lance ou lançante, que duas vezes por mês faz-se presente, era destinado à produção de aguardente. Essa atividade trouxe para a população do estuário, particularmente os municípios de Abaetetuba e Igarapé-Miri, até sua fase de declínio, bastante divisas, e gerou por aproximadamente cinco décadas, empregos em escala crescente, sendo comercializado em determinado momento em todo o estuário, até seu declínio irreversível na década de 70 do século XX.

Segundo Anderson (1991), o escoamento do produto por outros pontos do estuário dava-se através dos regatões, os quais usavam barcos que ainda não possuíam motor e navegavam aproveitando o fluxo e refluxo da maré e o auxílio de vela e, em alguns casos, eram utilizados barcos a vapor, herdados do chamado período da borracha, cuja transferência da produção gomífera pelo governo inglês para a Malásia, deixou a Amazônia em verdadeiro colapso.

Os ilhéus do estuário amazônico, particularmente os componentes da Comunidade São José do furo Maracapucu, praticam diversas atividades produtivas para garantir sua subsistência. Essas atividades concretizam-se a partir da exploração dos recursos disponibilizados pelo ambiente natural, obedecendo ao tempo, ciclos lunares e influência das marés. Observações que vem ao encontro do que afirma Lewis (1997), que as atividades agrícolas e pesqueiras dos ribeirinhos são influenciadas pelo ciclo sazonal.

Atualmente faz parte da cesta de produtos dos ilhéus do estuário, o cultivo e coleta do açaí, que se destaca na preferência dos ribeirinhos, 
em seguida a pesca artesanal, além de atividades outras como a prática de roçados de farinha, captura de camarão, tessitura de paneiro, corte e comercialização de lenha para abastecimento das olarias localizadas nas ilhas e padarias existentes na sede do município, cultivo de ervas, coleta de cascas de árvore, sementes, óleos e cipós usados na medicina popular; criação de pequenos animais ou sirimbabos. ${ }^{11}$ Como porcos, patos, além de mudas de plantas ornamentais, odoríferas e medicinais e outras especiarias que são consumidas pelos ilhéus e tem seu excedente comercializado.

Semelhanças são percebidas entre a sociedade ribeirinha amazônica, particularmente os ilhéus estuarinos da Comunidade São José do furo Maracapucu e a sociedade Esquimó do século XIX, das quais destacamse três: a primeira é na relação homem/natureza, pois a forma como essas duas distintas sociedades relacionam-se com o meio natural, caracteriza comportamento extrativista; a segunda constitui-se em função da primeira, é o desenvolvimento de um gênero de vida, influenciado pela disponibilidade dos recursos disponíveis no ambiente natural, necessários à sobrevivência; e uma terceira semelhança dá-se na importância e afinidade de um determinado recurso natural, para a reprodução dessas sociedades.

Observa-se que, assim como o ribeirinho amazônico, o esquimó se adapta às mudanças climáticas e sazonais e, com isso, construiu seu gênero de vida a partir da relação com o meio físico e suas variações.

Coletando, capturando, apanhando, derrubando, criando, cultivando e extraindo de acordo com o ofertado pela natureza, a exploração desses habitats exige não só um conhecimento aprofundado dos recursos naturais, das épocas das reproduções das espécies, mas a utilização de um calendário complexo dentro do qual se ajustam (DIEGUES, 2004, p. 84).

A produção do açaí é indispensável na reprodução da sociedade ribeirinha amazônica, assim como a foca, fruto da caça marinha, foi fundamental para a reprodução da sociedade Esquimó descrita por Marcel Mauss.

\footnotetext{
${ }^{11}$ Xirimbabo ou sirimbabo são criações de animais destinados ao consumo ou a venda em pequena escala elas famílias ribeirinhas; qualquer cria de estimação.
} 
Essa afinidade é tão marcante que Mauss (2003) destaca que onde há foca, deve haver esquimó. Em se tratando do ribeirinho amazônico, afirma-se que quando há açaí à mesa, o dia há de ser melhor.

As atividades econômicas de subsistência, fortemente influenciadas pelos ciclos da maré, as manifestações culturais que acontecem em temporalidades próprias, os diferentes cultos religiosos praticados pelas famílias do estuário amazônico são os meios pelos quais essa sociedade interage com o ambiente no tempo e no espaço, exercendo assim diversas formas de territorialidade.

A coleta do açaí destaca-se na preferência dos ribeirinhos. Sua afinidade com o açaizeiro (Euterpe oleracea) é tão intensa como é a relação com o gado para os Nuer ou mesmo, a Bruxaria para os Azande.

A relação do ribeirinho amazônico com o fruto é motivo de alegria e tranquilidade; ele é mercadoria com comercialização garantida. Segundo os ilhéus, no tempo do açaí, que acontece entre os meses de setembro e fevereiro, há uma circulação maior de dinheiro no estuário, aumentando, com isso, o poder de compra do ribeirinho.

$\mathrm{Na}$ safra do açaí surgem, nas ilhas de Abaetetuba, especialmente na Comunidade São José do furo Maracapucu, diversos atores sociais que compõem as relações de produção e comercialização como: meieiros, parceiros, marreteiros ou atravessadores e, formatos como a parceria, mutirão ou adjuntório que possibilitam a concretização das atividades.

Do açaizeiro, tudo se aproveita; do fruto, extrai-se o vinho, indispensável na alimentação local, consumido "in natura" e na forma de doce e licor; de suas sementes confeccionam-se bijuterias; de seu caule, faz-se assoalhos; sua raiz é utilizada na medicina popular, seu palmito é utilizado na culinária, suas folhas secas são utilizadas como combustível para a produção de farinha de tapioca; seu cacho serve para confeccionar vassouras e bonecas, a chamada çairoca, terra resultante da putrefação dos caroços, é usada como substrato na produção de mudas de planta.

Mesmo com tanta utilidade, a polpa do fruto ainda é a parte mais consumida, dada suas propriedades nutricionais. De acordo com Nogueira (1995, p. 14), no cultivo econômico do açaí, deve-se evitar as áreas pantanosas permanentemente alagadas, onde não ocorra a renovação constante da água. Compreende-se que os solos ribeirinhos, que são 
inundados pelas águas das marés, diariamente, possibilitam a formação de um ambiente propício para o cultivo do fruto.

A partir dos destaques quanto à produção e consumo do açaí, pode se afirmar que a água que hidrata e nutre o solo, contribui com desenvolvimento da palmeira, de onde o estuarino extrai o principal alimento e dá significado a sua vida, pois, para o ribeirinho, o cultivo do açaí está relacionado não somente com uma atividade de subsistência, mas como componente da cultura social e alimentar de um povo.

\section{Conclusão}

Para concluir ressalta-se que a vida no estuário amazônico, particularmente na Comunidade ribeirinha São José do furo Maracapucu, sob todas as suas formas: social, religiosa, cultural e produtiva, dependem diretamente da relação com a água, ou seja, o estudo possibilitou compreender a importância da água na crença, na locomoção, nos hábitos e atividades produtivas dos sujeitos.

Pôde-se enfatizar, por exemplo, a semelhança de outras culturas com a cultura ribeirinha, dentro de suas especificidades, mostrando a importância do ambiente e seus recursos naturais, entre eles à água, para a construção do gênero de vida. No entanto, este ambiente que pode influenciar na qualidade de vida do ribeirinho do estuário, vem sofrendo agressões de fontes diversas: poluição, contaminação, maus hábitos e ausência de programas e projetos governamentais, comprometidos amplamente com a reprodução da população do estuário.

Faz-se necessário, portanto, a presença mais atuante do poder público no estuário, no sentido de proporcionar alternativas de melhoria da qualidade de vida do estuarino, garantindo o desenvolvimento das comunidades, em todos os seus aspectos, com ênfase, no reconhecimento do valor da água para a cultura ribeirinha. 


\section{REFERÊNCIAS}

ANDERSON, Scott D. Engenhos na Várzea: uma análise de declínio de um sistema de produção tradicional na Amazônia. In: LÉNA, Philippe; OLIVEIRA, Adélia Engrácia (Orgs.). Amazônia: a fronteira agrícola 20 anos depois. Belém: Museu Emílio Goeldi/coleção Eduardo Galvão, 1991.

DIEGUES, A. C. O mito moderno da natureza intocada. $5^{\text {a }}$ Ed. São Paulo: Hucitec, 2004.

EVANS-PRITCHARD, E. E. Os Nuer: uma descrição do modo de subsistência e das instituições políticas de um povo Nilota. São Paulo: Perspectiva, 1978.

FURTADO, Lourdes Gonçalves. Pesqueiros Reais e Pontos de Pesca: traços da territorialidade haliêutica ou pesqueira Amazônica. Boletim do Museu Paraense Emílio Goeldi. Série Antropologia. n. 1, v. 18, jul., Belém: MCT/MPEG, 2002.

GALVÃO, Eduardo. Santos e Visagens: um estudo da vida religiosa de Ita, Baixo Amazonas. São Paulo: Editora Nacional, 1976.

HIRAOKA, Mário; RODRIGUES, Deborah L. Porcos, palmeiras e ribeirinhos na várzea do estuário do Amazonas. In: FURTADO, Lourdes G. (Org.). Amazônia: desenvolvimento, sócio diversidade e qualidade de vida. Belém: UFPA/NUMA,1997.

LEWIS, Biorn Maybury. Terra e Água: Identidade Camponesa como Referência de Organização Política entre os Ribeirinhos do Rio Solimões. In: FURTADO, Lourdes G. (Org.). Amazônia: desenvolvimento, sócio diversidade e qualidade de vida. Belém: UFPA/ NUMA, 1997.

LIMA, Walter Chile R. Ambiente e lugar: Estudo da Comunidade São José do Furo Maracapucu, Abaetetuba/Pará. Monografia. Belém: NUMA/UFPA, 2005. 
MACHADO, Jorge (Org.). O município de Abaetetuba: geografia, física e dados estatísticos. Abaetetuba: texto digitado, 2001.

Terras de Abaetetuba. Belém: Cejup, 1986.

MAUSS, Marcel. Ensaio sobre as variações sazonais das sociedades Esquimós. In: Antropologia e Sociologia. São Paulo: Cosac e Naify, 2003.

MOREIRA, Ruy. Sociabilidade e Espaço: As formas de organização geográfica das sociedades na era da Terceira Revolução Industrial - um estudo de tendências. Agrária. São Paulo, n. 2, 2005. pp. 93-108.

NOGUEIRA, Oscar Lameira et al. A cultura do açaí. Coleção Plantar. Brasília: EMBRAPA, 1995.

WAGLEY, Charles. Uma comunidade Amazônica: estudo do homem nos trópicos. São Paulo: Editora da Universidade de São Paulo, 1988. 